\title{
JOVENS GAYS NA ESCOLA: MASCULINIDADES, INFÂNCIA E NARRATIVAS
}

\section{- JULIANE COSTA SILVA}

Universidade do Estado da Bahia

\section{JANE ADRIANA VASCONCELOS PACHECO RIOS}

Universidade do Estado da Bahia

RESUMO O artigo apresenta histórias de escolarização de estudantes gays, especificamente, as marcas da infância e as questões das masculinidades vivenciadas nos espaços formativos da escola e da família. Trata-se de uma pesquisa narrativa, cuja opção metodológica inspirouse nos estudos da História oral, utilizando as entrevistas narrativas como dispositivo de recolha das histórias de vida. Os entrevistados foram seis estudantes gays do ensino médio de uma escola pública estadual, situada no interior da Bahia. O estudo revelou que os jovens gays reconstroem suas histórias de escolarização, em um processo de investigação-formação de si, ampliando os modos como se perceberam na infância, a partir das relações construídas na família e fortalecidas nas relações interpessoais com os colegas da escola que, através de apelidos pejorativos e de exigências para atender a um padrão de masculinidade hegemônica, acabam violentando os corpos infantis gays.

Palavras-chave: Masculinidades. Infância. Escolarização. Narrativas.

\section{ABSTRACT YOUNG GAYS IN SCHOOL: MASCULINITIES, CHILDHOOD AND NARRATIVE}

The article presents schooling stories of gay students, specifically childhood brands and issues of masculinity experienced in the formative spaces of the school and the family. It is a narrative research, whose methodological option was inspired by the studies of oral history, using narrative interviews as a device for collecting life stories. It was interviewed six gay high school students of a state school, located in Bahia. The study found that gay youth rebuild Their school stories in a process of self-investigation, expanding how They perceived Themselves in childhood, from relationships built on family and strengthened in interpersonal relationships with school classmates that through pejorative nicknames and the obligation to meet 
a pattern of hegemonic masculinity, end up violating gay children's bodies.

Keywords: Masculinities. Childhood. Schooling. Narratives.

\section{RESUMEN JÓVENES GAYS EN LA ESCUELA: MASCULINIDADES, INFANCIA Y NARRATIVAS}

El artículo presenta historias de escolarización de estudiantes gays, más específicamente, las marcas de la infancia y las cuestiones de las masculinidades vivenciadas en los espacios formativos de la escuela y de la familia. Se trata de una investigación narrativa, cuya opción metodológica se inspiró en los estudios de la Historia Oral, utilizando las entrevistas narrativas como dispositivo de recogida de las historias de vida. Los entrevistados fueron seis estudiantes gays de la escuela secundaria de una escuela pública estatal, ubicada en el interior de Bahía. El estudio reveló que los jóvenes gays reconstruyen sus historias de escolarización en un proceso de investigación-formación de sí mismos, ampliando los modos como se percibieron en la infancia a partir de las relaciones construidas en la familia y fortalecidas en las relaciones interpersonales con los compañeros de la escuela que, a través de apodos peyorativos y de exigencias para atender a un patrón de masculinidad hegemónica, acaban violando los cuerpos infantiles gays.

Palabras clave: Masculinidades. Infancia. Escolarización. Narrativas.

\section{Introdução}

Este trabalho discute as marcas da infância e as questões das masculinidades vivenciadas por estudantes gays, no ambiente escolar, apresentadas através das histórias de escolarização destes jovens na Educação Básica.' O texto é construído a partir dos estudos sobre Identidade e diferença de Hall (2004) e Silva (2014); Sexualidade e performance, à luz de Foucault (1988) e Butler (2013), e Masculinidades, com Aragão (2013) e Seffner (2003).

O espaço escolar é ocupado por conflitos, tensões e complexidades. No convívio en-

1 Este artigo é um desdobramento da pesquisa desenvolvida no Mestrado em Educação do Programa de Pós-Graduação em Educação e Contemporaneidade - PPGEDUC, na Universidade do Estado da Bahia UNEB. tre gestão, professores(as), estudantes, pais, mães, alunos(as), as questões de identidade, gênero e sexualidade são vividas de formas particulares. Presenciamos, nas últimas décadas, mudanças epistêmico-políticas envolvendo as comunidades LGBTQI, nas quais os seus sujeitos têm saído dos lugares de silenciamento e subalternidade para reivindicarem seus lugares de fala, em diferentes contextos, entre eles, a escola. É nesse cenário de luta e resistência que vivemos, sobretudo hoje, que os corpos gays têm buscado ocupar diferentes espaços e serem vistos e reconhecidos como sujeitos.

As histórias de vida têm possibilitado conhecer e produzir marcadores de sentido acer- 
ca dos processos de escolarização de diferentes sujeitos. Neste caso, específico, buscamos aqui as narrativas de seis estudantes gays do Ensino Médio de uma escola pública do interior da Bahia, para tratar das questões das masculinidades vividas na infância através da relação escola e família. A pesquisa que apresentamos é de natureza qualitativa, cuja opção metodológica inspirou-se nos estudos da História oral, especialmente na utilização do gênero história oral de vida. Como dispositivo de pesquisa, foi utilizada a entrevista narrativa, buscando compreender os sujeitos em seu contexto histórico, social e cultural.

Nesse interim, inicialmente, discutimos a questão da identidade e da diferença, a partir dos processos de negação, reconhecimento e estranhamento. Em seguida, apresentamos as questões da infância e suas marcas oriundas da família e da escola, analisadas através de narrativas de brincadeiras e silenciamentos. Por fim, trazemos as cenas narrativas de homofobia vividas na escola, entrecruzadas pela discussão acerca das masculinidades.

\section{Entre as janelas da escola: infâncias, identidades e diferenças}

Quando pensamos a diferença e suas interpelações na construção da identidade e do sujeito, olhamos a partir dos estudos epistemológicos do pós-estruturalismo. Desse modo, a diferença é vista como "essencialmente um processo linguístico e discursivo" (SILVA, 2009, p. 87). Isso porque a diferença é tecida nas relações de poder, em um caráter relacional, pois só em comparação com o outro é que ela se evidencia. As relações de poder institucionalizam a diferença como o lugar simbólico da exclusão. Os estudos pós-estruturalistas abriram um leque de possibilidades para olharmos as questões da diferença no espaço escolar. A partir dessa corrente, nos questionamos acerca da linguagem, do discurso e do texto.

O pós-estruturalismo procura entender como um discurso se consolida como verdade, os sentidos e o processo de significação que se inscrevem em um discurso e o legitimam como uma verdade. Através do pós-estruturalismo, mergulhamos nos estudos de Foucault (1988) e Butler (2013) e observamos que ambos se preocuparam em desconstruir e problematizar os discursos de verdade, uma vez que o primeiro questiona os discursos acerca da sexualidade e das relações de poder e, a segunda, as questões de gênero, como foram se construindo e se estabelecendo enquanto discursos de verdade. Os corpos experienciam modos de ser e viver que são influenciados por diferentes instituições, primeiro a família e depois a escola. Como podemos observar na narrativa de Marcelo:2 "Ela (a mãe) sempre acha não meu filho, é assim, meu filho é sensivel, ele vai crescer, ele vai mudar, entendeu? Pai não, pai quer que seu filho homem seja homem desde que nasce, desde que sai da barriga da mãe"

Desde cedo, os corpos são observados e pensados em uma divisão de gênero. 0 corpo inscreve-se discursivamente em uma rede que o insere automaticamente em um sistema binário. "Nascemos" homens e mulheres e, por isso, a família, que está inserida em diferentes discursos, acaba por reproduzir um cenário de representações em nossa criação. Assim, na experiência com a família, é que se constroem as primeiras representações de gênero que são vivenciadas pelos estudantes, sujeitos desta pesquisa.

"Oh, isso não é de homem, isso é de mulherzinha, você não é mulherzinha, você sempre foi homem, quando saiu da barriga de sua mãe, o médico disse que era um homem, não

2 Em consonância com o Termo de Consentimento Livre e Esclarecido - TCLE desta pesquisa, os nomes dos estudantes foram substituídos por codinomes escoIhidos por eles. 
era mulherzinha" (MARCELO). Falas como estas foram recorrentes nas narrativas dos estudantes. Eles vivenciaram, primeiramente, uma identidade que foi reconhecida pelo outro sobre o seu corpo: "você nasceu homem", o reconhecimento de si e de como iriam se construir futuramente foi interpelado discursivamente pela forma como a família os reconheceu e os identificou. Isto aparece logo no início das narrativas, quando suas falas abordam a construção da identidade sexual, antes de chegarem à escola.

Hall (2004), ao nos questionar: quem precisa de identidade? - nos desafia a perceber como vamos nos reconhecendo e nos estranhando em identidades que são fixadas aos nossos corpos. Se, como vimos, a partir dos estudos de Foucault (1988), a identidade está mediada pelas relações de poder, então, quem precisa dela? Para Hall (2004), uma das possibilidades de responder a esse questionamento é pensar que as críticas que são feitas à concepção de identidade, ao se configurarem como desconstrutivistas, não anseiam por uma substituição, mas colocam o conceito de identidade a prova, problematizando, desconstruindo. Sendo assim, não procuramos trabalhar aqui com um conceito de identidade, uma vez que: "Não há conceito simples. Todo conceito tem componentes, e se define por eles. Tem, portanto uma cifra. É uma multiplicidade, embora nem toda multiplicidade seja conceitual" (DELEUZE; GUATTARI, 1992, p. 26). Trazemos algumas abordagens sobre identidade que dialogam entre si, e nos potencializam para discutir a concepção de diferença. Afinal, a identidade como um conceito é, portanto, ao mesmo tempo absoluto e relativo: relativo a seus próprios componentes, aos outros conceitos, ao plano a partir do qual se delimita, aos problemas que se supõe deva resolver" (DELEUZE; GUATTARI, 1992, p. 33)

Pensar, portanto, a questão da identidade torna-se ainda mais delicado, quando a asso- ciamos à ideia de uma identidade sexual, uma vez que os estudantes gays nos revelam que os conflitos, entre a expectativa de gênero e o estabelecimento de uma identidade que é imposta pelo outro, começam a questionar tal imposição, a partir de pequenas situações de confronto consigo mesmo.

Eu sempre olhei pra os homens com um olhar diferente do que olhava para as meninas, porque eu fui criado muito pelas minhas primas e pela minha mãe, então a convivência com mulheres pra mim era comum, ver o corpo feminino exposto ou nu era uma coisa normal pra mim. Já o homem não, já tinha um mistério, já tinha uma coisa assim que eu não sabia o que era. $(\text { MAYCOON })^{3}$

As primeiras sensações de reconhecimento do corpo do outro que é igual em termos biológicos é um dos primeiros conflitos com as identidades impostas, a diferença se expressa na forma como eles veem os corpos e se sentem em relação ao outro que é igual. Hall considera que não precisamos de uma teoria cognoscente do sujeito, mas de uma teoria das práticas discursivas, ou seja, precisamos reconfigurar o conceito de sujeito, pois "é preciso pensá-lo em sua nova posição - deslocada ou descentrada - no interior do paradigma" (HALL, 2004, p. 105). É através desse processo de reconceitualização do sujeito que a questão da identidade, ou mesmo da identificação, se assim preferirmos denominar, volta a aparecer no cenário das discussões.

É através dessa concepção de um corpo, que se associa a uma identidade que está interligada à questão do gênero, que foram tecidas a concepção de uma identidade sexual que está sintonizada a um gênero instituído e a um sexo biológico natural. Falar sobre identidades sexuais remete-me à premissa de que, em si, o próprio conceito de identidade não é

3 Os excertos textuais das narrativas dos jovens gays fazem parte do acervo de entrevistas que foram coletadas durante a pesquisa de Mestrado. 
uno, mas flexível e plural. Desse modo, quando tomo a ideia de uma identidade sexual, faço essa mesma reflexão, uma vez que ela não é fixa e estável, mas se desloca e é vivenciada em pluralidades de experiências e sentidos. Assim, como não a pensamos em um binarismo, em uma identidade heterossexual e outra homossexual, mas como a possibilidade de diferentes formas de se identificar que o sujeito reconhece em si, por isso falamos hoje em um movimento LGBQI.

Nenhuma identidade sexual - mesmo a mais normativa - é automática, autêntica, facilmente assumida; nenhuma identidade sexual existe sem negociação ou construção. [...] Em vez disso, toda identidade sexual é um construto instável, mutável e volátil, uma relação social contraditória e não-finalizada. (BRITZMAN, 1996, p. 40)

As ameaças que chegam ao estudante gay são oriundas não apenas da família, pois no espaço da escola as marcas das diferenças são vividas, desde muito cedo. Assim, uma vez observadas, elas viram motivo de chacota e cena de tensões. "Eu já sofria tanto bullying, tanta coisa que, ao decorrer do tempo, eu fui ficando cada vez mais frágil. Mais recluso mesmo. Eu não tinha amigos, eu não saía de casa" (MAYCOON). A diferença passa a ser silenciada, como uma questão política e subjetiva. 0 corpo ocupa um não lugar no reconhecimento de si, através do desconforto provocado pelo olhar do outro.

No momento em que o corpo começa a se defrontar com as diferentes formas de se expressar, em confronto com a norma, percebemos que o corpo se revela aos poucos, como algo inacabado. Esse desencontro, entre a norma e a forma como os estudantes se veem, demarca os primeiros conflitos consigo mesmos. Eles são julgados, controlados e classificados a partir dos padrões de referência e normas que são instituídos socialmente. Isto apare- ce nas narrativas, a partir dos modelos de ser menino e menina instituídos pelas famílias, e ao chegarem à escola. A subversão à norma traz para estes sujeitos diferentes processos de constituição identitária e de formas de lidar com as diferenças. A subversão do modelo estabelecido produz marcas em suas histórias de vida, uma vez que aqueles que "subvertem as gestualidades, as vestimentas e os comportamentos de gênero são classificados como homossexuais, ordenados como desviantes e desvalorizados na hierarquização social" (SANTOS, 2011, p. 52).

A construção do lugar do outro atravessa os elementos constitutivos da identidade dos estudantes gays. "O outro é a condição de perpetuidade do simbolismo que o atravessa. 0 outro é a estrutura que organiza a ordem de significado do mundo" (LE BRETON, 2006, p. 37). É no olhar com/para o outro que eles vão construindo a relação com o mundo e com os campos simbólicos. Nos reconhecemos e nos estranhamos a partir do outro; assim, os estudantes vão integrando diferentes grupos, construindo as relações de pertencimento. É neste movimento que os estudantes se deparam com situações de negação do outro a sua identidade sexual: "Na terceira série eu me lembro de uma briga que eu tive com um menino, exatamente, por isso, a gente caiu no tapa mesmo porque ele me chamou de veadinho e eu não gostei e a gente começou a brigar" (MAYCOON).

Os apelidos representam a forma mais comum de agredir e (des)caracterizar os corpos. Nas entrelinhas do discurso que classifica os corpos em veados, bichas e gays, as demarcações de poder e privilégio são evidenciadas. Os meninos, como vimos na experiência de Maycoon, são classificados desde muito cedo; as marcas do corpo que se diferenciam são descaracterizadas e este passa a ser visto como inferior. 
Aí nas minhas escolas assim que eu estudei, tem uma escola aqui, no Parque do $\mathrm{S}$ eu acho que pra mim foi a melhor escola que eu estudei até hoje porque a diretora de lá ela via quem eu era, entendeu? Eu chegava na escola, eu tirava o sapato, eu calçava o salto dela, e ela nunca chegou pra meu pai pra contar, nunca! Ela perguntou, ela chegou, conversou comigo, ela sentou comigo, ela conversou, o que é que eu sentia quando eu fazia aquilo, mas ela nunca contou pra meu pai, ela nunca chegou pra chegar assim: "olhe, fulano, seu filho é assim e assim". (MARCELO)

Quando Marcelo conta a experiência inicial com a escolarização acerca da sua sexualidade, ele demarca em sua narrativa dois lugares para a diferença: o primeiro é construído na perspectiva do (re)conhecimento, no momento em que a diretora se aproxima do estudante para procurar entender a construção de sua sexualidade; a segunda é a diferença vigiada, presente no interdiscurso da narrativa, em que este processo é acompanhado pela diretora, visto e revisto em alguns padrões de ser menino e menina, construídos socialmente.

Nas relações com as identidades diferentes, no ambiente da escola, os estudantes começam a vivenciar seus primeiros olhares diferentes sobre si mesmos, o que chamamos aqui de estranhamentos. A escolha pela terminologia estranhamento deu-se pela forma como os próprios jovens falam de si, do modo como foram se defrontando com a contradição de uma identidade imposta e uma identidade negada. A diferença reconhecida reverbera no sujeito como uma provocação, levando-o a se questionar, a tentar entender o que se passa com seus desejos e sensações. Buscar entender o porquê de certos comportamentos que incidem em tantas represálias. "Eu me sentia estranho, não conseguia entender por que olhava para os meninos de maneira diferente, eu não sabia o que era, mas sabia que era diferente" (MAYCOON).
Para entender o que chamamos de estranhamento, precisamos buscar referências em fontes distintas. Primeiramente, compreendemos que o estranho poderia estar associado à própria leitura da Teoria Queer, que, ao ser traduzida, traz a provocação de levar para a cena de discussão aqueles que foram marginalizados, excluídos, não reconhecidos socialmente, estranhos diante de uma "suposta normalidade". Pensamos o sujeito gay como aquele que se estranha diante de um padrão de masculinidade, mas que é também estranhado em um ambiente reconhecidamente heterossexual.

Apropriamo-nos do conceito do estranho também a partir dos estudos de Butler (2013) e Louro (2008), uma vez que a partir da Teoria da performatividade, o corpo gay é aquele que vivencia um gênero que não está engendrado nos discursos. Assim, uma vez que seu desejo se expressa por um corpo semelhante ao seu, ele foge a um padrão de linearidade entre sexo - gênero. “O gênero é performativo porque é resultante de um regime que regula as diferenças de gênero. Neste regime os gêneros se dividem e se hierarquizam de forma coercitiva" (BUTLER, 2002, p. 64).

Nessa perspectiva, Louro (2008), ao apresentar a ideia de um corpo estranho, nos provoca a pensar sobre esse corpo que incomoda o outro, por se apresentar desviante das normas de uma heterossexualidade considerada natural. Assim, o estranho também representa aquele que se desloca e que vivencia outras experiências acerca do gênero e da sexualidade; o estranho é o outro diante de um padrão maciço de naturalização da sexualidade. Compreendemos que esse estranhamento revela em si a sensação de deslocamento dos padrões sociais instituídos. Assim, nessas diferentes práticas, a infância e os corpos são marcados por uma tentativa de entender esses estranhamentos. 


\section{Escola e família: espaços de poder}

Segundo Foucault (2009), a sociedade fabrica diferentes dispositivos de construção/manutenção do biopoder, isto é, instrumentos e discursos que são responsáveis por disciplinar os corpos e controlá-los. Nesse ínterim, a sexualidade é um importante instrumento para a manutenção do biopoder, através de quatro entradas discursivas que, historicamente, analisaram o sexo: a histerização do corpo da mulher, a pedagogização do sexo da criança, a socialização das condutas de procriação e a psiquiatrização do prazer perverso. Tais discussões tornaram-se pautas dos estudos de Foucault (1988) acerca da sexualidade e da arqueologia do poder e foram responsáveis pela vigilância de sujeitos específicos, como a mulher histérica, a criança masturbadora, o casal malthusiano e o adulto perverso, principalmente o homossexual.

O prazer de vigiar, controlar e fiscalizar, mas também o de criar mecanismos de fuga desse poder, de revelar-se, ou mesmo de tentar esconder o que não deveria ser visto. o poder é alimentado pelo prazer de perseguir, mas é um poder que se configura à medida que o sujeito consegue subverter esse poder de controle. Nesse sentido, a sexualidade, durante o século XIX, esteve marcada pelo eixo poder-prazer, que se perpetua até os dias atuais. Segundo Louro (1999, p. 7), são muitos os que "consideram que a sexualidade é algo que todos nós, mulheres e homens possuímos 'naturalmente'. Aceitando essa ideia, fica sem sentido argumentar a respeito de sua dimensão social e política ou a respeito de seu caráter construído". Essa acepção nos faria entender o sexo como algo pronto e inerente ao ser humano, ou seja, todos vivenciariam a sexualidade de uma maneira universal e seríamos biologicamente determinados a vivê-la de acordo com o sexo biológico. Porém, como podemos ver nos estudos foucaultianos, a sexualidade constitui-se como um dispositivo histórico, em meio a discursos de controle e normatização.

O controle sobre as brincadeiras é uma das manifestações do controle sobre a criança, deixando claro para ela, desde muito pequena, que estamos inscritos em uma sociedade binária. Entre o azul e o rosa, a boneca e o carrinho, Marcelo foi separado dos brinquedos pela visão biológica acerca do gênero e ensinado a se comportar em conformidade com tal padrão. Os corpos começam a ser fabricados, e não existe um corpo livre do elemento discursivo.

A evocação que se faz do corpo, quando a criança nasce, irá determinar, ao longo da sua vida, a forma como ela será vista e interpelada socialmente; o menino que nasce biologicamente com a genitália masculina está determinado a experimentar todos os discursos de construção de um homem socialmente aceito. Assim, qualquer sinal de um comportamento que insinue ou mesmo remeta a qualquer ideia que construímos do universo feminino é negado e silenciado por diferentes práticas. Dialogando com essa questão, Bento (2006, p. 88) afirma que:

Quando o médico diz: ‘é um menino/uma menina', produz-se uma invocação performativa, nesse momento, instala-se um conjunto de expectativas e suposições em torno desse corpo. É em torno dessas suposições e expectativas que se estruturam a performances de gênero.

Nesse sentido, a família e a escola são instituições responsáveis pela manutenção dessas práticas, uma vez que através dos brinquedos e brincadeiras vão inscrevendo as concepções de gênero e sexualidade; vigiamos os banhos e as brincadeiras, distinguimos o que pertence ao mundo da menina e do menino. Se na família a vigilância é grande em torno do sexo e das expressões masculinas, na escola, essa experiência muitas vezes se torna cada vez 
mais dolorosa. Na vivência com outros colegas, ficam mais evidentes as diferenças e isso alimenta práticas permeadas pela exclusão e o silenciamento.

$\mathrm{Na}$ escola, os estudantes gays são, desde cedo, classificados e rotulados. Vivenciaram práticas de exclusão que iam desde a proibição das crianças de brincar com aqueles que tinham gostos por brincadeiras diferentes até o comportamento de hostilidade e crítica de professores diante das opções feitas sobre os brinquedos e as brincadeiras. Na experiência com a escola, Harry Potter afirma que era necessário ser menos feminino para ser aceito, uma vez que o menino que não apresentava trejeitos mais femininos não era questionado em sua sexualidade. Segundo Louro (1999, s.n.), “o homem 'de verdade', nesse caso, deveria ser ponderado, provavelmente contido na expressão de seus sentimentos. Consequentemente, podemos supor que a expressão de emoções e o arrebatamento seriam considerados, em contraponto, características femininas".

$\mathrm{Na}$ concepção de um homem que deve atender a determinados princípios sociais, os estudantes gays vivenciam constantes cenas de desrespeito e preconceitos. Eles foram silenciados e negados pela ideia de um sexo que normaliza os comportamentos. Diante de uma prática constante de apelidos e rejeições, os meninos vão construindo modos violentos e solitários de lidar com esta questão, numa luta pela negação de si.

Eu cresci muito recatado, eu cresci muito para mim. Eu nunca chorei com ninguém, eu chorava comigo. Eu ia para meu quarto a noite, às vezes chorava sozinho. $E$ às vezes quando uma prima minha, um primo vinha conversar comigo, eu contava, mas contava distorcido do que tinha acontecido, só para ter uma sensação de desabafo, um pouco, entendeu? Que era aquele meio desabafo, não era aquele desabafo completo, omitindo as partes que eram mais importantes para você. (MARCELO)
Para Marcelo, contar os apelidos e as violências de gênero que sofria na infância era contar que ele se sentia diferente e que seu desejo não atendia à expectativa da família. As violências deixam marcas inscritas na subjetividade dessas crianças que, desde muito cedo, convivem com as piadinhas dos colegas e dos familiares sobre as diferentes formas de se expressarem. Uma violência que muitas vezes não é revelada à própria família.

Como já vimos até agora, os jovens - sujeitos desta pesquisa - vão sendo interpelados por diferentes fatores durante a sua escolarização, entre eles: as construções e negações das identidades, os silenciamentos e o estranhamento. Os meninos que ocupam os espaços da escola e da família, com seus corpos que expressam diferentes formas de viver a sexualidade, geram um desconforto e levantam uma série de questões acerca da masculinidade, do preconceito e da homofobia.

\section{Masculinidades em questão: um desafio}

Discutir acerca das masculinidades ainda é um campo novo na ciência, uma vez que, somente a partir dos movimentos feministas e do movimento gay, passamos a questionar a estabilidade das identidades sexuais. Quando pensamos em masculinidades, nos remetemos aos aspectos hegemônicos de construção da função masculina, uma vez que são associadas à masculinidade as características que compõem essa identidade do ser homem.

Diante das tensões contemporâneas e dos deslocamentos das identidades e dos sujeitos, algumas características vão se descentrando desse conceito hegemônico de masculinidade, pois, se ao homem não era permitida a vaidade com o seu corpo, o boom de recursos e produtos direcionados à estética masculina ajudam a romper os padrões e deslocam o 
conceito. Assim, precisamos pensar a masculinidade como algo que tem se deslocado. Segundo Connel (1995, p. 188), a “masculinidade é uma configuração de práticas em torno da posição dos homens na estrutura de gênero". Uma prática que se exerce em um significado histórico, ou seja, à medida que repetimos discursos sobre os corpos, eles assumem práticas que os condicionam a uma representação de gênero.

Seffner (2003, p. 121) afirma que o questionamento da masculinidade hegemônica só pode ser entendido no âmbito de uma perspectiva de transformações mais gerais das relações de gênero, e não como crise particular da masculinidade. Sob essa perspectiva, nas histórias de escolarização dos estudantes, a infância aparece em suas projeções da masculinidade não como uma crise do ser homem, ou ser masculino, mas das transformações pelas quais esses meninos passaram durante as suas trajetórias e que interpelam a maneira como vão representando suas masculinidades.

As inscrições discursivas sobre os corpos impõem uma forma de viver o sexo-gênero de maneira unilateral. Desse modo, os estudantes - colaboradores desta pesquisa - foram iniciados em brincadeiras típicas de meninos e de meninas, que simbolizaram o primeiro conflito desses sujeitos em suas relações com o mundo.

Eu sofri na infância por causa disso, que meu pai sempre queria impor, "Não! Isso não é de homem! Oh, isso não é de homem, isso é de mulherzinha, você não é mulherzinha, você sempre foi homem, quando saiu da barriga de sua mãe, o médico disse que era um homem, não era uma mulherzinha". (MARCELO)

A narrativa de Marcelo nos faz repensar uma questão relevante para o estudo das masculinidades, a construção do masculino. Como vimos até agora no texto, no momento em que os corpos nascem, eles são inscritos discur- sivamente em diferentes papéis de gênero. 0 gênero masculino, por sua vez, é desenhado a partir de uma concepção do ser homem que direciona cada sujeito da pesquisa a vivenciar determinados modos de comportamento. 0 masculino é construído e ensinado ao sujeito, mesmo que se pressuponha que ele, ao nascer biologicamente homem, já traga isso inscrito em si. Você é homem, pois nasceu homem.

Os conceitos de masculino e masculinidades confundem-se, nesse processo discursivo, e passam a ser sinônimos um do outro, porém o que não é questionado, ainda naquele momento em que os meninos narram suas histórias, é a ideia de que a masculinidade não é única, mas múltipla, assim como não existe uma construção do masculino, mas jeitos diferentes de existir que não cabem em uma simples denominação binária como masculino e feminino.

O ser/estar/existir biologicamente como homem insere cada sujeito em um campo subjetivo de diferenciação. Assim, se à mulher foram ensinados, durante muito tempo, os deveres da casa, ao homem foi destinado o trabalho fora dela. Essas marcações históricas vão determinando os corpos. Assim, crescer numa sociedade sexista estabelece padrões e normas que uma vez subvertidos soam o alarme de um possivel deslocamento de lugares. Uma vez que esses deslocamentos são percebidos, aumenta-se a vigilância e o controle, aspectos a que se refere Foucault (1988), e a família torna-se responsável por controlar e punir qualquer manifestação de subversão.

Sempre gostei de ajudar minha mãe nos afazeres de casa e as pessoas já viam aquela diferença, aquela coisa, tanto que vizinhos comentavam né, sempre falavam uma coisa ou outra, e isso já me feria um pouquinho. Apanhei muito na minha infância, através de meu padrasto, eu sentia uma diferença dele comigo, mas ainda assim ia levando tudo numa boa ia para a igreja. (PEQUENO PRÍNCIPE) 
0 auxílio às atividades domésticas subvertia os modos de vivenciar sua masculinidade. É comum ouvirmos que realizar trabalhos domésticos é coisa de mulher, mesmo vivendo em uma sociedade com tantos discursos de desconstrução dos papéis sociais. As diferentes formas de controlar e vigiar se evidenciam nessa situação através das surras aplicadas pelo padrasto, referência doméstica do ser homem. Assim, o ato de bater que reprimia o corpo para que ele não exercesse atividades não associadas ao masculino, mas correspondesse à expectativa daquele sexo-gênero. Essa é apenas uma das formas de se expressar a violência física, simbólica e psicológica, sobre a criança que se afasta dos modelos preestabelecidos.

A relação com a família diante do estranhar-se e reconhecer-se como diferente frente aos padrões que determinam os rótulos e os desejos, não foi fácil para Pequeno Príncipe, assim como não foi para Marcelo. Após a separação dos pais, Marcelo passou a viver com o pai e a madrasta. Sem o convívio com a mãe e diante das duras repreensões do pai sobre o jeito de comportar-se, ele aprendeu desde cedo que certos comportamentos não eram permitidos em sua presença, porém, já na sua ausência, as brincadeiras ditas como femininas eram permitidas.

Para Maycoon, que nunca sofreu na família a força de um padrão de masculinidade, sua diferença sempre foi muito natural, "eu sempre fui uma criança muito feminina, um menino, eu sempre fui um menino magrinho, frágil e de voz fina". Criado em um ambiente predominantemente feminino, para Maycoon, sua aproximação ou mesmo os trejeitos ditos como femininos sempre foram algo natural. Não existia o reforço de um padrão masculino e, sendo assim, o defrontar-se com outros jeitos de ser menino só reverbera em outros espaços.
Neste caso, foi no processo de escolarização que Maycoon vai se defrontando com outros reconhecimentos das masculinidades. Um jeito de ser menino que está associado à ausência da expressão de seus sentimentos e a comportamentos ríspidos que fortalecem a ideia de um homem como sendo o macho. Assim, Maycoon percebe desde muito cedo, na educação infantil, que a forma como age e se expressa, ou mesmo sua preferência pelas brincadeiras e pela companhia das meninas expressava uma forma diferente de se perceber como menino. Podemos observar essa questão na fala de outro entrevistado, Allan Malaquias.

Sempre gostei de andar com as meninas, brincava com elas e tudo mais. Mas minha atração, minha sina, eram os meninos. Desde muito cedo, muito novo. Eu era um menino que jogava futebol e fazia essas brincadeiras mais de meninos, mas já tinha uma tendência para o lado feminino. 0 meu comportamento era feminino, as minhas posturas, o meu vestuário tinha uma tendência de ser de menina e os meus pais eles nunca interviram. (ALLAN MALAQUIAS)

As marcações de gênero ganham visibilidade nas narrativas, pela distinção sobre o que pertence aos universos feminino e masculino, que a todo o momento são referenciadas. A demarcação de ser um menino com trejeitos de menina acompanha grande parte das narrativas. É esse reconhecer-se como um menino com jeito e trejeitos femininos que nos leva a refletir sobre o estranhamento do sujeito e as diferentes masculinidades.

O silenciamento existente entre o afeto, o desejo e a autovigilância determina o modo como os meninos vão lidando com sua autodescoberta. Ensinados, policiados, ou vivendo de maneira livre suas descobertas percebemos que os apelidos pejorativos dos vizinhos e familiares se faziam presentes, em vários momentos da trajetória desses estudantes, 
principalmente na história daqueles que apresentam trejeitos femininos, como nos revela Marcelo, ao recordar de experiências vividas no colégio: "ser chamado de bichinha, veadinho, era algo recorrente nas minhas lembranças do colégio e até mesmo na brincadeira com os outros vizinhos. Sempre fui agredido dessa forma, eu só chorava" (MARCELO).

O ser homem tem se inscrito socialmente em um projeto de vigilância e de oposição ao outro, que é submisso e fragilizado. Considerados os algozes, na análise da opressão feminina, durante muito tempo, não investigamos o ser homem como uma forma discursiva que oprime também os sujeitos que transgridem a concepção engendrada do homem como o ser forte e opressor. Nessa perspectiva, a figura do homem foi desenhada como aquele que foi responsável, historicamente, pelas desigualdades de gênero. 0 estudo sobre as masculinidades observa os modos de vida que instituem um "jeito de ser homem" ou mesmo "tornar-se homem". Nessa perspectiva, "ao falar de masculinidade não falamos apenas de personagens ou características individuais, mas de toda organização de práticas sociais e instituições formadoras" (ARAGÃO, 2013, p. 344) que sedimentam os gêneros, nesse caso de estudo, o homem.

A partir dos estudos de Aragão (2013), compreendemos que a masculinidade transcende o corpo biologicamente masculino. Assim, o corpo social compartilha os valores da masculinidade ou feminilidade, independente do sexo biológico. Desse modo, quando acompanhamos as histórias desses jovens, percebemos que o movimento que fazem da compreensão de si mesmos perpassa pela interpelação de uma masculinidade que foi imposta a partir de práticas sociais que também geram processos de identificação em alguns deles

A experiência de masculinidade vivida por esses jovens reverbera de maneiras diferen- ciadas e sobre diferentes olhares. Em outras palavras, a masculinidade hegemônica só resiste na precariedade das masculinidades minoritárias, ou seja, uma vez que os meninos são forçados a assumir uma experiência de masculinidade, as outras expressões de masculinidades começam a ser silenciadas, pois são vistas como desviantes. Porém, o fato de se identificarem como gays ou homossexuais, não anula o reconhecimento desses meninos dos papéis instituídos socialmente:

Acho que o processo de construção sexual, da sexualidade, é totalmente subjetivo, e tem relação com o que você vive e o que você se identifica, o que você gosta de fazer, e com quem você se relaciona. Eu me vejo homem, eu sou homem, porém minha sexualidade é homossexual, gosto de outros homens. (ALLAN MALAQUIAS)

A narrativa de Allan Malaquias nos revela que mesmo que transgridam os padrões de sexualidade e de masculinidade, os meninos continuam a se identificar como homens, pois a própria categoria deve ser entendida como um posicionamento político. O colocar-se e reconhecer-se como homem independe da sua sexualidade, pois ele se reconhece em relação aos direitos e ao lugar social desse homem. Afinal, as minorias sexuais e o reconhecimento de seus direitos e identidades ainda são silenciados. No entanto, o lugar social do masculino é reconhecido como um sujeito de direitos.

Entre uma masculinidade hegemônica, que reivindica o lugar de prestígio, e uma masculinidade subordinada, que reivindica os seus direitos, vamos alimentando uma sociedade preconceituosa. As piadas e expressões pejorativas constituem-se, não apenas como uma prática homofóbica, mas uma punição àquele que não exerce da mesma forma sua masculinidade. Uma vez que a masculinidade hegemônica se alimenta de uma sociedade patriarcal, na qual a mulher é sua subordinada, 
o homem que apresente trejeitos femininos vê-se submetido a constantes sinais de violência simbólica. Ou seja, o homem com trejeitos femininos será por sua vez uma masculinidade subalterna.

Durante o período de escolarização, principalmente nas séries iniciais do ensino fundamental, "tende-se, nesse momento, a enfatizar a reclusão ao prazer, a negar a sexualidade infantil, o diálogo, salientando a desinformação, o medo, os tabus e preconceitos em torno da sexualidade sem culpabilidade" (SOUZA, 1994, p. 9). Isso por que ainda perpetuamos de alguma forma a negação de uma sexualidade que se expressa desde a infância. Construímos a ideia de um corpo, não apenas naturalizado em sua sexualidade, mas sem sexualidade, durante a infância. Assim, os corpos assumiriam uma sexualidade apenas na adolescência, quando falaremos sobre os hormônios e como eles alteram o corpo e, assim, a sexualidade aflora. Porém, conforme podemos observar na narrativa a seguir, não é bem assim que ocorre:

Eu desde criança me sentia atraído sim por outros caras, mas eu achava que era normal. Tipo todo mundo ia passar por aquela fase na adolescência também, mas quando os hormônios afloraram, como dizem, aí pronto, é o baque. Poxa, eu não pensava nem nos meus pais, nem na sociedade, eu pensava no inferno, eu vou para o inferno. (HARRY POTTER)

Quando a escola e a família corroboram com uma formação que acontece a partir da repetição dos discursos, os efeitos vivenciados por esses sujeitos gays são sentidos como Harry Potter descreve, a ideia de uma sexualidade que aflora com os hormônios e que o desperta para a busca de si, mas também o medo. O medo do inferno, da sua sexualidade como anormalidade.

O discurso propagado pela escola de uma não sexualidade infantil traz efeitos não ape- nas para os estudantes gays, mas para toda uma sociedade que, como contrapartida da discussão sobre uma sexualidade, forma cada vez mais uma sociedade heterossexista. E aí se configura a contradição.

O ambiente escolar é um espaço fundamental no processo de socialização do indivíduo, marcando a transição da infância à adolescência. Sendo assim, deve se caracterizar por ser um local seguro, que oferece proteção ao jovem, além de prepará-lo para o futuro e apresentar um eficaz processo de ensino-aprendizagem, sempre primando pelo bem-estar dos seus alunos. (SILVA; BARRETO, 2012, p. 11)

O que temos visto, a partir das narrativas, é que a escola, nos anos iniciais e no ensino fundamental II, é vivenciada de maneira muito dolorosa pelos meninos. Vale ressaltar, entretanto, que não queremos fortalecer a ideia de uma escola essencialmente preconceituosa e cheia de tensões, mas reconhecer que a escola que ganha vida nas histórias desses meninos traz essa marca de preconceito e exclusão. “Eu brincava muito de boneca na escola, vivia com as meninas, porque os meninos não queriam brincar comigo. Eu fui muito xingado, queriam me bater. Até pelos professores mesmo, me viam diferente e me olhavam diferente" (PEQUENO PRÍNCIPE).

As relações com os colegas e professores demarcam uma linha tênue entre a escola vista como um espaço hostil ou de acolhimento, porque é no momento da vivência de relações interpessoais, com os colegas e docentes, que os meninos experimentam as marcas de escolarização que invisibilizam e rotulam os sujeitos. Por mais que a escola tente negar a sexualidade dentro do seu espaço, ela existe e se faz presente, em diferentes situações. A sexualidade pulsa na escola, mesmo que dela pouco se fale. As crianças e adolescentes possuem suas sexualidades, independente da visibilidade ou não que isso ganhe nas discussões em sala de 
aula. Ela está nos corredores, nas paredes, nos banheiros, nas relações entre os pares.

Eu lembro que na educação infantil um menino me chamou para o fundo da escola e ele me beijou, sem maldade. Eu não entendi por que ele fez isso. Eu fui apenas por que ele me chamou. Eu não sentia um preconceito dos professores, até por que eu me segurava 73 muito, eu me segurava meio que para não "soltar a franga". (HARRY POTTER)

A partir das narrativas desses meninos, a escola vai se revelando como o espaço que tem pensado pouco sobre a sexualidade infantil, que não a tem pensando como algo presente na vida dos sujeitos, mas algo que surge posteriormente, em outros momentos da história desses estudantes. Em contrapartida, quando escutamos as narrativas, percebemos que há uma contradição entre a visão de infância que a escola tem trabalhado e a real relação da infância com a sexualidade.

Eu lembro que no colégio eu sempre estava na frente da dança e do teatro. E isso incomodava muito minha avó, ela ficava dando testa à professora, pois as professoras diziam que ela deveria me colocar na escola de teatro, porque eu me destacava sempre, mas minha avó fazia o trocadilho dizendo que "na família já tinha muito artista". (MENINO DE LUZ)

A avó vigilante de Menino de Luz ia à escola cobrá-la e alertá-la sobre o seu papel de guardiã da sexualidade e da masculinidade do neto. Permitir que ele se destacasse e que estivesse envolvido e fosse o centro nas atividades comumente associadas ao universo feminino não fazia parte dos planos da avó para ele. Assim como Marcelo precisou se afastar do grupo de dança, na escola, por causa dos colegas e, posteriormente, por causa do pai, Menino de Luz também é controlado e vigiado em suas práticas de socialização. Como nos afirma Butler (2013), a sexualidade se constitui como a ideia do corpo vigiado, controlado e performático. 0 corpo que precisa ser negado em suas expressões.

As humilhações constantes sofridas no ambiente escolar revelam, nas narrativas, que à medida que a escola se torna uma experiência hostil para esses meninos, seus desempenhos escolares não são satisfatórios. Ter que lidar com questões de homofobia, práticas de xingamento e de destruição do seu material escolar mostra a forma como esse estudante vai se relacionando com a escola, com os saberes. O seu desempenho escolar é fraco e o aluno apresenta notas baixas, dificuldades de concentração e nas formas como passa a se relacionar com os colegas.

A rejeição ao aluno gay expressa-se, também, na negação e na culpabilização daquele estudante. Ele se torna o problemático e aquele que desperta o motivo da violência. A ausência de posicionamento da gestão é representativa do olhar que aquela instituição tem para com o aluno. Ao negar as situações de violência e proteger os agressores, a escola reproduz um discurso de preconceito e que reforça o dispositivo de controle sobre tais alunos. Essa situação gera momentos cada vez mais dificeis para o aluno gay. Apoiada em um discurso que historicamente naturalizou os corpos, a escola se vê como a responsável por continuar a alimentar esse discurso e, por vezes, tem dificuldade em tentar fazer diferente, com receio do julgamento que a sociedade possa ter sobre ela.

As narrativas nos mostram que é nesse momento de vida escolar, a educação infantil e do ensino fundamental, que os meninos mais sofrem com as situações de violência e silenciamento diante das situações de preconceito. Assim, é nessas circunstâncias que os dispositivos de poder mais se fazem presentes. É na relação com a escola, em suas fases iniciais de escolarização, que esses meninos vão construindo suas relações com o outro e consigo 
mesmos. Diante disso, os meninos vão se tornando jovens, reconhecendo seus desejos e preferências, constituindo-se sujeitos através da hermenêutica de si, citada por Foucault (2012). É nos desencontros com os colegas, nos estranhamentos de seu jeito de ser menino e na compreensão de sua masculinidade e de como ela se expressa que os sujeitos vão se defrontando com outras questões: qual o seu lugar ou não lugar na escola?

\section{Considerações finais}

Longe de tentarmos responder a questão, qual o lugar do aluno gay na escola, nos propomos nesse texto a pensar quais os lugares, sentidos e experiências que eles têm vivido em seus processos de escolarização. A escola constituída em suas diferenças, nem sempre está apta a reconhecer e lidar com essa diferença. Os estudantes gays são apenas uma parte dessas questões que precisam ser problematizadas na escola. É preciso, primeiramente, que a escola reconheça que existe uma questão a ser discutida. E que a discussão de gênero e sexualidade está longe de ser uma questão externa, mas ela se inscreve em suas práticas cotidianas.

Ser gay na educação básica, para esses estudantes pesquisados, tem representado, nesse momento específico, uma experiência de violência, contradições, silenciamentos e estranhamentos. Nas práticas que se estendem da família à escola, os estudantes são marcados subjetivamente por estranhamentos que machucam suas subjetividades, mas que também os interpelam a resistir àquele espaço.

A infância, assim, aparece como esse momento em que tudo se torna mais intenso de ser vivido, os apelidos pejorativos, o isolamento dos colegas, o silêncio dos professores frente às situações de violência, tudo só reforça a ideia de um não lugar para esses sujeitos na escola. Ao mesmo tempo, as narrativas nos levam a pensar que é na percepção de ser diferente que esses jovens, naquele momento vivido, começam a descobrir seus gostos, afetos, limitações e formas de subverter a ordem de masculinidade imposta.

Sujeitos de masculinidades diferentes, eles aprendem no dia a dia a negociar com suas masculinidades subalternas e a entender como o corpo vai sendo inscrito em um discurso de gênero e sexualidade que impõe uma masculinidade tóxica. É neste sentido que buscamos aqui o protagonismo dos estudantes gays, a fim de compreender as suas histórias de vida como fundadoras de outras bases epistêmico - políticas para a educação

\section{Referências}

ARAGÃO, Rafael. O homem é desse mundo: para entender a masculinidade como um processo histórico. In: COLLING, Leandro; THÜRLER, Djalma. (Orgs.). Estudos e política do CUS - Grupo de Pesquisa Cultura e Sexualidade. Salvador: EDUFBA, 2013.

BENTO, Berenice. A reinvenção do corpo: sexualidade e gênero na experiencia transexual. Rio de Janeiro: Garamond Universitária, 2006.

BRITZMAN, Debora P. O que é esta coisa chamada amor - identidade homossexual, educação e currículo. Revista Educação \& Realidade, Porto Alegre, v. 21, n. 1, p. 71-96, 1996.

BUTLER, Judith. Problemas de gênero: feminismo e subversão da identidade. Tradução de Renato Aguiar. Rio de Janeiro: Civilização Brasileira, 2013.

BUTLER, Judith. Como os corpos se tornam matéria. Entrevista a Baukje Prins e Irene Meijer. Revista de Estudos Feministas, v. 8, n. 2, p. 15-16, 2002.

CONNELL, Robert W. Políticas da masculinidade. Educação e Realidade, Porto Alegre, v. 2, n. 20, p. 185-206, jul./dez. 1995.

DELEUZE, Gilles; GUATTARI, Félix. 0 que é a filosofia? Tradução de Bento Jr. e Alberto Alonso Muñoz. Rio 
de Janeiro: Ed. 34, 1992.

FOUCAULT, Michel. História da sexualidade I: a vontade de saber. Tradução de Maria Thereza da Costa Albuquerque e J. A. Guilhon Albuquerque. Rio de Janeiro: Edições Graal, 1988.

FOUCAULT, Michel. A arqueologia do saber. Rio de Janeiro: Forense Universitária, 2009.

FOUCAULT, Michel. A ordem do discurso: aula inaugural no Collège de France, pronunciada em 2 de dezembro de 1970. Tradução de Laura Fraga de Almeida Sampaio. São Paulo: Edições Loyola, 2012.

HALL, Stuart. A identidade cultural na pós-modernidade. 9. ed. Rio de Janeiro: DP\&A, 2004.

LE BRETON, David. A sociologia do corpo. Petrópolis, RJ: Vozes, 2006.

LOURO, Guacira Lopes, Um corpo estranho - Ensaios sobre sexualidade e teoria queer. Belo Horizonte: Autêntica Editora, 2008.

LOURO, Guacira Lopes. Pedagogias da sexualidade. In: (Org.). 0 corpo educado: pedagogias da sexualidade. Belo Horizonte: Autêntica, 1999. p. 07-34.

SANTOS, Raquel Alexandre Pinho dos. Isso é o que não mudou ainda: diversidade sexual, homofobia e cotidiano escolar. 2011. 134 f. Dissertação (Mestrado em Educação) - Departamento de Educação, Ponti- fícia Universidade Católica do Rio de Janeiro, 2011.

SEFFNER, Fernando. Derivas da masculinidade: representação, identidade e diferença no âmbito da masculinidade bissexual. 2003. 261 f. Tese (Doutorado em Educação) - Programa de Pós-Graduação em Educação, Universidade Federal do Rio Grande do Sul, Porto Alegre, 2003.

SILVA, Tomaz Tadeu da. Identidade e diferença: a perspectiva dos estudos culturais. Tomaz Tadeu da Silva. (Org.). Stuart Hall, Kathryn Woodward. Petrópolis, RJ: Vozes, 2014.

SILVA, Tomaz Tadeu da. Documentos de identidade: uma introdução às teorias do currículo. Belo Horizonte: Autêntica, 2009.

SILVA, Joilson Pereira da.; BARRETO, Nayana Santana. Violência escolar: problematizando a relação entre o bullying e a homofobia. Revista Fórum Identidades, Itabaiana: GEPIADDE, ano 6, v. 12, p. 1-15, jul./dez. 2012.

SOUZA, Elizeu Clementino de. A escola e a sexualidade: porque negar o prazer? Revista Brasileira de Estudos Pedagógicos, Brasília, v. 75, n. 179; 180; 181, p. 450-467, jan./dez. 1994.

Recebido em: 12/03/2019

Aprovado em: 22/05/2019

Juliane Costa Silva é Doutoranda do Programa de Pós-Graduação em Educação e Contemporaneidade. Professora Substituta da Universidade do Estado da Bahia - UNEB. Membro do Grupo de Pesquisa Docência, Narrativas e Diversidade na Educação Básica - DIVERSO. e-mail: julianec.letras@gmail.com

Rua Conselheiro Junqueira, Cond. Viva Alagoinhas, bloco 31, apto. 303 - Rua do Catu - Alagoinhas/BA. CEP: $48090-020$. Telefone: (75) 998741406.

Jane Adriana Vasconcelos Pacheco Rios é Pós-Doutora em Educação pela Universidade de São Paulo - USP. Doutora em Educação pela Universidade Federal da Bahia - UFBA. Professora Titular da Universidade do Estado da Bahia - UNEB. Professora do Programa de Pós-Graduação em Educação e Contemporaneidade - PPGEDUC/UNEB. Líder do Grupo de Pesquisa Docência, Narrativas e Diversidade na Educação Básica - DIVERSO. e-mail: jhanrios1@yahoo.com.br

Avenida Cardeal da Silva, 523 - Ed. Liliana, apto. 703 - Federação - Salvador-Bahia-Brasil

CEP: 40.230.305 Fone: (71) 99204-3623 